\title{
Determinants of Collaborative Leadership: Civic Engagement, . Gender or Organizational Norms?
}

\author{
CINDY SIMON ROSENTHAL, UNIVERSITY OF OKLAHOMA
}

This analysis attempts to unravel competing explanations of collaborative leadership styles of state legislative committee chairs. Specifically, the paper considers the influence of community or volunteer experience, gender, and institutional variables. The data show that women chairs are more likely than their male peers to cite as valuable the leadership skills and experiences that they gain through community and volunteer experience. Compared to their male colleagues, women committee chairs on average also report a greater reliance on collaborative strategies in the management of their committees. Prior community or volunteer experience has little or no direct effect on collaborative styles. In contrast, institutional factors have a much stronger and countervailing influence. Legislative professionalization produces a strong negative effect on collaborative style. Results suggest that conformity to institutional norms may be a more compelling influence than prior community experience. The analysis also points to the gendered nature of organizational leadership with men's and women's styles showing different associations to style depending on the number and power of women in a legislature.

The current discussion of "social capital" focuses on the decline of trust and civic engagement among the general public (Putnam 1993, 1995). Putnam principally focuses on mass political participation, but a largely unexplored corollary of Putnam's work is the connection between civic engagement and the leadership styles of political elites or officeholders. Putnam predicts that "past success at collaboration . . can serve as a cultural template for future collaboration" (1995: 67). If some organizations more than others "effectively embody - or generate - social capital, in the sense of mutual reciprocity, the resolution of dilemmas of collective action, and the broadening of social identities" (1995: 76), then officeholders who have such experiences may

Political Research Quarterly, Vol. 51, No. 4 (December 1998): pp. 847-868 
be expected to be collaborative in their leadership approach. If Putnam is correct, one might hypothesize that prior volunteer or community experience will increase the likelihood of collaborative leadership behavior on the part of elected officials.

Putnam defines "social capital" as "features of social life - networks, norms, and trust - that enable participants to act together more effectively to pursue shared objectives" (1995: 664). The gist of Putnam's argument is that joining and trusting go hand in hand (e.g., the more people get involved in community life, the more they trust others) to produce social capital which, in turn, fosters norms of "coordination and cooperation for mutual benefit" (1995: 67).

This study explores the link between experiences of civic engagement and collaborative styles of leadership while controlling for other possible explanations of collaborative leadership. To be sure, many officeholders hone their political leadership skills in community activities. Verba, Schlozman, and Brady (1995: 310) make this point when they note that "Those who enter the higher levels of politics . . . have almost always developed civic skills at work, in non-political organizations, or in church. ..." But it is also true that community activism has been a more common route for women into politics than for men (e.g., Darcy, Welch and Clark 1987; Thomas 1994; Dolan and Ford 1997). Moreover, political behavior cannot be divorced from its institutional basis (March and Olsen 1989).

Focusing on state legislative committee chairs, this analysis looks at their pre-political experiences of civic engagement. Are some experiences more typical of women committee chairs? Are those experiences associated with behaviors that advance a collaborative style of leadership? Are there legislative institutional factors that might be more important influences on leadership style?

\section{Gender, Civic Engagement, and Leadership}

Gender is a key dimension in Putnam's analysis. Women have been important participants in organizations central to civic engagement, but as Putnam points out, women's entrance into the paid workforce parallels the decline of voluntary group membership. Gender has also been offered as an explanation to greater understanding of the dynamics of organization behavior and collaborative styles of leadership.

In the late nineteenth century and continuing into the twentieth, the women's club movement, volunteer work, and civic activism drew women into politics (Woloch 1994; Adams 1921; Clemens 1993), provided opportunities for women to develop leadership skills (Scott 1993), and launched the electoral careers of many women officeholders (Fletty 1951). Indeed, the 
temperance and the women's club movements "invigorated their members... politicized their leaders, [a]nd . . . created a separate space for women in public life" (Woloch 1994: 287). Not the least of these organizations were the Woman's Christian Temperance Union (WTCU), which was established in 1873 and had grown by 1911 to over 245,000 members (Woloch 1994: 288), and the General Federation of Women's Clubs, which was founded in 1890 and had over one million members by 1910 (Clemens 1993: 760). In a parallel club movement engaging African-American women, the National Association of Colored Women founded in 1896 and the Colored Women Voters Leagues emerging in the deep South in the 1920s pushed for suffrage and social reforms (Jones 1990: 117). Because of the social, racial, and occupational caste system historically evident in the South, "political women's work" took different forms for African-American women than for whites and placed black women in the 1950s in a "special role in [the civil rights movement] both as 'private nurturers' and as 'public' leaders" (Jones 1990: 126).

Club activities soon became "a springboard to civic boards or public office" (Fletty 1951: 35). For example, the National League of Women Voters launched the careers of Chase Going Woodhouse, Emily Taft Douglas, Helen Gahagan Douglas and Eleanor Roosevelt. In its Election Handbook published in 1946, league authors referred to the organization as "a school in which women leaders are trained" (13). Similarly, the American Association of University Women (AAUW) believed that "women could ... ensure the nation an expert, rational, and democratic leadership" and thus "sought ways to enable women to reach their individual potential, become leaders in their communities" (Levine 1995: 1-2). Even while Putnam documents a steady post-World War II decline in civic club membership, women's groups have continued to be an important avenue for women in politics. As Darcy, Welch, and Clark (1987: 33) reported, "A common finding has been that women local officeholders have a history of civic activity, including . . leadership roles in the PTA and the League of Women Voters." Moreover, a "second wave" of women's organizations has moved beyond white, middle-class constituencies to draw women of color, lesbians, and others more visibly into politics since the 1970 s (Ferree and Martin 1995). Nonetheless women of color comprise less than 3 percent of state legislators (CAWP 1996).

In addition to providing opportunities for individual women, women's groups introduced new models of political participation and organization (Clemens 1993). While imitating some features of corporate and bureaucratic organizations, women's groups also developed more culturally "feminine" forms of organization emphasizing educational lobbying, democratic decision making, familial relationships, and personal service or altruism (Clemens 1993: 776-77). Some feminist organizations of the 1970 s explicitly rejected hierarchy, 
embraced collectivist decision making, and sought to empower their members (Ferree and Martin 1995). During the conservative 1980s, however, some established national women's organizations adjusted their organizational procedures and tactics as they struggled to balance their feminist ideals with the desire to achieve pragmatic policy goals (Spatter-Roth and Schreiber 1995: 125). The maturation of the feminist movement gave rise to "modified consensus" as a form of organizational governance in some women's interest groups (Iannello 1992: 118-19).

While collaborative norms of operating have been a unique part of women's networks of civic engagement, other research also associates women with more collaborative styles of leadership. This kind of leadership - less hierarchical and more consensual - has been shown to be preferred by women leaders and managers (e.g., Lunneborg 1990; Rosener 1990; Cantor and Bernay 1992; Helgesen 1990; Jewell and Whicker 1994.) For example, Jewell and Whicker (1994: 182) conclude "Women [legislative leaders] . . . were more likely to develop a consensus leadership style than were men." The overall tendency reported in their study is that "in state legislatures as well as in corporations and other settings, leaders are moving toward more consensual, conciliatory, systems-oriented leadership types" and this trend may "facilitate the entry of women into leadership positions in the future" (188). Similarly, Helgesen (1990: 258) concludes collaborative, nurturing, and inclusive leadership styles as opposed to traditional, hierarchical modes of leadership are today being successfully utilized in the corporate world as well as non-profit agencies. One problem with studies claiming women to be more collaborative in style, however, is their relatively small samples and comparison of quite dissimilar positions.

This analysis improves upon these studies by looking at a larger group of political leaders with similar duties. The study also takes into account institutional factors that might affect leadership behavior. Various scholars posit that leadership behavior is situational or contingent on organizational factors (e.g., Fielder 1967; Hersey and Blanchard 1977). Moreover, some scholars argue that organizations are gendered (Acker 1992), meaning that men and women experience organizations differently, have different leadership and power resources (Duerst-Lahti and Kelly 1995), and face varying pressures of visibility, boundary heightening, and tokenism (Kanter 1977). Of specific import to this analysis are the number and power held by women in a legislature. Kanter's seminal work suggests that when women move beyond token representation their presence will begin to change an organization's culture. Yoder (1991), however, notes that sometimes an organization's dominant group, in this case men, will resist "token" individuals because they are intruders who threaten existing 
norms. More recently, Duerst-Lahti and Kelly (1995) have stressed the need to focus on the impact of gender power rather than simply numbers. Both power and numbers of women are considered in the analysis.

The data focus on state legislative committee chairs, a population that offers several advantages. First, the nature of committee work and the role of committee chairs involves perhaps the most collegial work of a legislature, work that might draw upon or benefit from experiences developed through civic engagement. Committee chairs have limited formal powers, but rather must rely upon interpersonal skills to negotiate, persuade, and reconcile different perspectives and goals. Second, state legislative committee chairs represent a sizable cohort of women leaders to allow for a larger study population. Finally, the role and duties of committee chairs are fairly similar from state to state and thus facilitate some comparisons.

This analysis attempts to explore different factors that might contribute to a collaborative style of leadership. Three hypotheses are advanced: (1) women committee chairs are expected to be more collaborative in their committee leadership style than men; (2) chairs with important community and volunteer experience (i.e., pre-political civic engagement) are expected to be more inclusive and collaborative in their committee leadership style than those who attach little significance to such pre-political experiences; and (3) different features of legislatures will be more favorable than others to collaborative modes of committee leadership.

\section{Methodology AND BACKGROUND}

This exploratory analysis is part of a larger study involving three complementary data sources: (1) a 1994 mailed survey of male and female committee chairs from 50 state legislatures; (2) focused peer group interviews involving 38 committee chairs ( 12 men, 26 women) conducted in 1994 and 1996; and (3) interviews, field work and direct observation of 29 committee chairs (15 women, 14 men) in Colorado, Ohio, and Oklahoma during legislative sessions in 1995. The focus groups and state investigations were used to provide observed behavioral measures that mitigate against distortions due to social desirability in survey self-descriptions. The triangulated research strategy was intended to balance problems of external validity associated with survey data only. This article draws principally on the survey data, but references confirmatory interview and focus group data where appropriate.

The questionnaire asked chairs to: (1) provide demographic and career data; (2) assess their leadership traits and behavior; (3) describe frequency of certain behaviors in one's role as a chair; and (4) relate attitudes about conflict, power, ambition, and peer relationships. The mailed survey was sent to all 353 women and a systematic random sample of 516 men drawn by state. The sample of men 
represents about one-fourth of all men who chaired standing or statutory committees as of March 1994. Completed surveys were received from 135 women, a response rate of 39.0 percent, and 156 men, a response rate of 30.5 percent. ${ }^{1}$ Each chair received the initial mailing and a follow-up reminder. The women were over-represented in the study population and had a second follow-up letter in an effort to produce a sufficiently large sample to allow for analysis.

Comparing the female respondents with non-respondents and comparing the male respondents with the population of all male chairs, no significant substantive differences were found in terms of committee chaired. ${ }^{2}$ The survey respondents compare quite favorably with committee chairs in terms of party. In the sample, 54.1 percent of the women chairs are Democrats compared to 60.4 percent of their male colleagues. In January 1993, the CAWP reported that Democratic women constituted 61.5 percent of all women legislators and 64.4 percent of all women committee chairs, while Democrat men comprised 58.0 percent of all legislators and 69.5 percent of all male chairs. ${ }^{3}$ No gender bias is evident among the states in terms of responses. The number of women who completed the survey in a state was significantly and positively correlated the number of female legislators in a state $(r=.512, p=.000)$. The survey respondents also match the gender proportions of chairs from legislatures

1 Mailing lists of the National Conference of State Legislatures were used to identify committee chairs as of March 1994. Lists were organized alphabetically by state and sorted by sex allowing every fourth male committee chair to be selected. To maximize returns, special endorsements were obtained; letters included personalized notes; and followup contact and mailings were done. The primary factor contributing to the higher response rate among women was one additional follow-up letter (two to the women and only one to the men). The response rate is based on the original sample minus questionnaires returned as undeliverable or the individual was no longer a committee chair.

2 The Council of State Governments' Directory of Legislative Leadership, Committees and Staff 1993-1994 was used to identify committees in nine jurisdictional categories. Using these categories, the survey respondents were compared with the nonrespondents (in the case of women) and with the population of all male chairs. With one exception, no statistically significant differences were found in terms of committee jurisdiction. A disproportionately low number of women chairing general government committees completed the survey ( 12 percent of all female respondents as compared with 27 percent of all women chairs). No substantive theoretical import is attached to this anomaly, however. Excluding the category of general government committees, cross-tabulations comparing committees chaired by female respondents and nonrespondents showed no significant difference between respondents and nonrespondents.

3 Party data reported by the Center for American Woman and Politics is based on the CSG Directory 1993-94 which is published in January 1993. The mailing lists were current as of March 1994, and several changes in party control (e.g.,Wisconsin and Florida) account for a slightly more Republican population of committee chairs at the time of the survey. 
of different legislative development (Kurtz 1992) ${ }^{4}$ The committee chair sample also compares favorably to other studies of state legislators in terms of respondents' age, educational attainment, race, and marital status (e.g., Woo 1994; Thomas 1994; Dolan and Ford 1997). ${ }^{5}$

\section{The Profile of Survey Respondents}

Women committee chairs differ from their male colleagues in ways that are similar to findings of scholars who studied women state legislators in the 1970s, 1980s and 1990s (e.g., Thomas 1994; Ford and Dolan 1997). Female committee chairs on average are older than their male colleagues when first elected (43.7 years compared with 39.8 years old, $\mathrm{p}<.001$ ). Women chairs are less likely to have young children at home - only 20.0 percent still had children under 18 living at home compared with 42.5 percent of the male committee chairs $(\mathrm{p}<.001)$. Only 13.4 percent of women committee chairs compared with 35.1 percent of their male colleagues have obtained professional degrees (e.g., MD, MBA, and JD). Five times as many women as men reported having no employment outside of the home prior to entering legislative service (22.0 percent compared with 4.1 percent, $\mathrm{p}<.001$ ).

In terms of their legislative careers, women committee chairs differ in important ways from male committee leaders. Women are significantly more likely to consider themselves full-time legislators: 64.9 percent of the women compared with 37.3 percent of the men $(\mathrm{p}<.001)$. Women chairs on average have fewer total years of legislative service than their male colleagues (10.2 years compared with 13.1 years, $\mathrm{p}<.001)$ and thus also have one less year of service as a committee chair ( 3.5 years compared with 4.7 years, $p<.01$.) Women on average are appointed chair after fewer years of legislative experience ( 5.1 years compared with 6.1 years for men, $p<.10$ ).

4 Cross-tabulations comparing female respondents and female nonrespondents in citizen, somewhat professionalized and highly professionalized legislatures showed no significant difference, and similar comparison of male respondents and the population of male committee chairs in the three categories of legislatures revealed no significant differences between the survey respondents and the population of committee chairs.

5 Since there is no national data base documenting the backgrounds of state legislators, comparisons were made to other studies such as Woo's (1994) survey of 900 lawmakers in 16 states, Thomas' (1992) study of 322 legislators in 12 states, and Dolan and Ford's (1997) cohort of 1990 legislators. This sample compares favorably in terms of respondents' age, educational attainment, marital status and race. For example, using Woo (1994) as a comparison group, 32.3 percent of chairs in the sample have at least a college degree (compared with 35 percent of Woo's 900 legislators), 79.2 percent are married (compared with 83 percent); the average age of committee chairs is 53.6 years (compared to 50). Almost 95 percent of chairs report their racial background as Caucasian (compared with 90 percent of legislators). 


\section{Variables}

An open-ended survey question was used to capture experiences of civic engagement. Committee chairs were asked to identify the "experience, either professional, volunteer or otherwise, [that] has most prepared you for being a committee chair." The responses were coded into six categories reflecting a range of experiences including volunteer and community, prior government experience, and professional background. Respondents frequently cited more than one preparatory experience and therefore answers were coded to multiple categories when appropriate. Seventy-three percent of the male respondents (112) provided 160 different responses; and 73 percent of the women (98) provided 183 responses. A dummy variable was created for each type of experience (e.g., 1 = community/ volunteer experience, $0=$ no community/volunteer experience cited). Chairs who did not answer the question did not vary from those who did in any significant way, therefore missing values were also coded zero. ${ }^{6}$

The dependent variable consists of a scale of ten items measuring specific behaviors and attitudes consistent with a collaborative committee leadership style. Four items focus on behaviors related to one's committee or other committee chairs. Specifically, a chair was asked to report how often: "I consult my vice chair on important matters before the committee," "I share strategic and political information with the committee," "I work closely with other chairs," and "I let other committee members take the lead on important committee bills." The response categories included: "almost never," "rarely," "sometimes," "often," and "almost always." Three items were adapted from the Thomas-Kilmann Conflict Mode Instrument. ${ }^{7}$ As conceptualized by the instrument, collaboration in conflict situations includes both cooperation with others and personal assertiveness to solve shared problems and to integrate leader-follower concerns. Thinking specifically about conflict situations, a chair was asked how often he or she "stresses direct discussion of issues of conflict," "shares

6 In addition to comparisons of demographic characteristics of chairs who answered the open-ended question and those who did not, multiple regression was used to rule out the possibility of any significant difference. A dummy variable coded " 1 " for those chairs who had missing values on the question was entered into a regression model along with all of the variables reported in Table 3. The results were essentially identical to those reported in Table 3 and no significant difference was associated with the dummy variable.

7 The Thomas-Kilmann Contlict Mode Instrument (1974) is well-established in the field of organizational behavior, The authors of the instrument report average alpha coefficients for each of the five styles of .60 . The authors also report evidence of substantive validity based on concurrent tests of four conflict-handling instruments that suggest convergence around the five modes in Thomas' theory. According to reviews of the instrument in The Tenth Mental Measurement Yearbook (1989), the Thomas-Kilmann 
problems with the other person so that we can work it out," and "tries hard to find a fair combination of gains and losses for all sides." Finally, three items assessed an other-directed orientation implicit in collaboration. Committee chairs were asked how strongly they agreed with statements that the chair's role represents an opportunity to "get people involved," "pull people together," and "share my power with others."

The ten items were summed for scale score of collaborative committee behavior. The scale has an Alpha reliability of .75. Given that the ten items all used five-point response categories, scale scores could range from a low of 5 to a high of 50. The mean score for the scale was 38.3 (s.d. 5.0.).

Several control variables are used in the analysis to assess other possible influences on collaborative management style. The norms of a legislature (some being part-time citizen assemblies and others more professionalized bodies) may affect a committee chair's style. Indeed, Stivers (1993) has argued that gender images of masculinity are deeply embedded in more bureaucratic forms of governance and the norms of professionalism. Professionalization in legislatures is commonly measured by such organizational dimensions as staffing, time resources, and policy capacity and is associated with legislator professionalism, expertise, and specialization that may encourage individual entrepreneurship more than pursuit of collective efforts (Rosenthal 1996: 183). In this analysis, Squire's (1992) index of professionalization, which is based on measures of legislator pay, staff members per legislator, and total days in session, is utilized. Squire notes that the "measure calculated is designed to show how closely a state legislature approximates the professional characteristics of the Congress" (71).

A second control variable reflects the sex composition of the legislature. Kanter (1977) argues that the proportions of minority and majority groups affect norms of organizational behavior. Thus the percentage of female members in the legislature is included. As hypothesized by Kanter (1977), the presence of more women may change norms of behavior. If women are more likely to be associated with collaborative styles, then more women legislators should be associated with more collaborative committee management behaviors on the part of male colleagues. At the same time, more female legislators do not necessarily represent more like-minded women (Dolan and Ford 1997), so we should not be surprised to find that more women in a legislature might have little effect on collaborative styles among women.

instrument when compared to similar organizational behavior instruments has the highest reliability coefficients and the lowest variance in scores that can be attributed to factors of social desirability. Only the items indicative of a collaborative style are used in this analysis. The other styles of conflict resolution include competition, avoidance, accommodation and compromise and they vary in degree of cooperation with others or assertiveness of one's own goals. 
In addition, a variable measuring women's power is included. Power is more than women's proportion of seats in a legislature. As Norton (1995) has noted, "it is not enough to be elected," women must hold positions of power to have some substantive or strategic opportunities to collaborate on policy. Power in this analysis is based on the percentage of committee chairs held by women in a state and the percentage of women serving in legislative leadership positions (CAWP 1993). Since committee chairs and leadership positions are not easily equated, both measures were standardized as z-scores and then summed, and the resulting sum was again converted to a $z$-score. In accordance with Yoder's (1991) intrusiveness hypothesis, more women's power is expected to produce resistance, and thus less collaborative committee styles, on the part of male committee chairs. As Norton (1995) might predict, more women's power should be associated with more collaborative leadership on the part of women.

Personal factors also are likely to influence collaborative or inclusive behavior. Putnam (1995: 674) speculates that life cycle, generational, and period effects may play a role in explaining the decline of social capital, thus the analysis controls for the committee chair's age and total years of legislative serviced. ${ }^{8}$

\section{Findings AND ANALysis}

\section{Differences in Civic Engagement}

Women committee chairs are much more likely to cite community/volunteer experiences as formative influences on their committee leadership approach. Table 1 reports the percentages of committee chairs who cited different experiences as important preparation for their roles as chair. Among those who identified pre-political experiences, more than 53 percent of the women cited the importance of community/volunteer work compared with little more than 14 percent of the men. As a subset of the whole sample, almost 36 percent (48 of 135) of the women cited volunteer and community work while only 10 percent ( 15 of 154 ) of men did. Cross tabulations of community/volunteer experience by sex produced a Pearson $\chi^{2}$ statistic of 35.89 , d.f.1 $(\mathrm{p}<.001)$.

8 Political culture - particularly a moralistic culture that values broad-based political participation (Elazar 1966) -was also hypothesized to play an influence on the production of civic engagement. Sharkansky's (1969) linear conversion of Elazar's political culture was used as variable in initial analyses of the data because it offers the advantages of recognizing blends of political cultures. More moralistic cultures (represented by a high score on Sharkansky's continuum) were expected to be associated with more collaborative norms. The political culture variable showed no effect in the analysis and was omitted from the reported results in the interests of parsimony. 


\section{$\equiv$ TABLE 1}

InFluences on a Chair's Committee Leadership Style

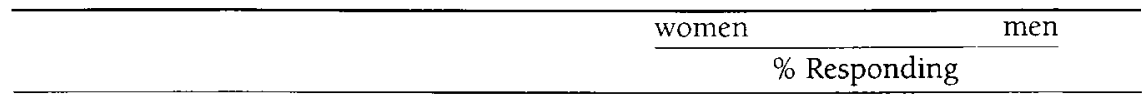

Preparatory Experience Cited by Committee Chairs

Professional ${ }^{1}$

Legislative

Prior Govt/Political Office

Community/Nolunteer Work

${ }^{\mathrm{a}} \mathrm{p}<.05 .,{ }^{\mathrm{b}} \mathrm{p}<.01 .,{ }^{\mathrm{c}} \mathrm{p}<.001$ based on Pearson $\chi^{2}$ statistic.

${ }^{\mathrm{I}}$ Includes all job or work-related experiences including business occupations, teaching, union positions, and military service. Number of respondents who completed the question included 98 women and 112 men.

In the field state interviews, four times as many women committee chairs as men (12 women compared to 3 men) cited skills learned in community/volunteer experiences such as church work, fratemal groups, and organizations such as PTAs, the League of Women Voters, or the American Association of University Women. The networks formed through such experiences represent precisely the kind of civic organizations that Putnam (1995: 67) identifies as creating social capital and encouraging mutual reciprocity and collaboration. Typical of the kind of statement made by women chairs is the comment of a Minnesota woman who wrote on her survey: "Being a parent, active in the League of Women Voters, my volunteer work with teenage parents and my teaching all gave me a background in understanding issues and I learned how to build consensus and make sound use of time."

\section{Differences in Collaborative Style}

To what extent does community/volunteer experience or sex contribute to a collaborative leadership style? Table 2 reports the mean scale score for all chairs by sex and by community/volunteer experience. The pattern of results reflects the hypothesized effect of sex and community experience on collaborative styles of behavior. Women chairs on average score 4 standard deviations higher than men on the collaborative scale. Chairs who cited community/volunteer experience on average score 3 standard deviations higher than those of chairs who did not cite community/volunteer experience as important leadership preparation. The differences on the mean scores are statistically significant but quite small in simple bivariate analysis. 
$\equiv$ TABLE 2

Effects of Sex and Community/Volunteer Experience on Collaborative Leadership Style

Collaborative Scale Scores

Differences by Sex***

Women

Men

Com/Volunteer Experience*

Yes

No $\bar{x}$

39.4

37.4

39.5

38.0 (s.d.)

146
$\mathrm{N}$

121

(1)

\begin{tabular}{cccc} 
Yes & 39.5 & $(4.4)$ & 63 \\
No & 38.0 & $(5.1)$ & 204 \\
\hline
\end{tabular}

${ }^{*} \mathrm{p}<.05,{ }^{* *} \mathrm{p}<.01,{ }^{* * *} \mathrm{p}<.001$ on two-tailed significance in $\mathrm{t}$-tests for difference of means.

Might community/volunteer experience have a different effect on men and women? Hierarchical analysis of variance was used to assess the main effects of sex and community/volunteer experience on collaborative leadership style and to explore a possible interaction between these variables. The combined main effects of sex and community/volunteer experience on a chair's collaborative style are significant $(F=6.42, p=.002)$. When the main effects of sex and community/volunteer experience are disaggregated, however, only sex is a significant predictor of collaborative style ( $F$ $=11.69, \mathrm{p}=.001$ ) and community/volunteer experience is not. No interaction effect is apparent between community experience and sex; in other words, community/volunteer experience has the same modest positive influence on both men and women.

The focus groups and personal interviews suggest more strongly the predisposition toward a collaborative leadership style on the part of women. Among the women interviewed, a consensus converged: female committee chairs on average are more likely to use collaboration, to invite open discussion of disagreements, and seek consensus rather than simple compromise. Some men agreed with that conclusion while others did not. In Ohio, for example, one chairwoman emphasized a desire to be more inclusive of as many points of view on an issue as possible, to find a win-win solution, and to use nontraditional decision-making strategies such as facilitator-mediated dispute resolution. ${ }^{9}$ By contrast, one of her male colleagues preferred to "develop

9 Patrick Field, "State legislators use consensus-building to resolve issues, involve citizens, develop legislation." Consensus, July 1994. 
my own solution to a problem, have it drafted, drop it in the hopper and watch everyone scream. ${ }^{10}$ His strategy is intended to get the attention of all interested parties, force the opposition to prepare and raise their strongest arguments, and then negotiate compromise as needed. This particular woman reflects a more collaborative or other-directed style while the man's philosophy illustrates a highly assertive, more personally controlling style.

In sum, these results provide only partial support for the hypotheses that civic engagement provides a template for future collaboration and that women as a group are more collaborative. The bivariate differences between men and women on the measure of collaborative style are not great, however. Moreover, the civic engagement results should be interpreted cautiously given the small number of male committee chairs (15) who highlighted community involvement as important background preparation to their role as chair.

\section{Multivariate Analysis of Leadership Determinants}

Might other variables, particularly organizational factors, provide a more powerful explanation of committee leadership styles? Alternatively, might institutional factors be masking a more substantial sex difference? Might gender be implicated in other ways? To probe these questions, multivariate analysis was performed using variables of: a dummy variable for sex (female $=1$ ), Squire's (1992) legislative professionalization score, the percentage of women in the legislature, women's power in the legislature, the dummy variable for community/volunteer experience, and a legislator's age, party, and total years of service. In addition, two interaction terms (\% Female Legislators $\mathrm{x}$ Sex and Women's Power $\mathrm{x}$ Sex) were used to assess the possibility that male chairs might respond differently than female chairs to the presence and power of women legislators. Table 3 reports the results of this analysis.

The multivariate analysis suggests that gender and organizational factors have an important impact on collaborative committee leadership, but community/volunteer experiences do not. Controlling for other factors, women are significantly more collaborative in their committee styles $(b=8.40, p=$ .009). The unstandardized coefficient for sex represents the difference between men and women chairs when the two variables that interact with gender (\% of Women and Women's Power) are both valued zero, (i.e., hypothetically in a legislature that has no female members.) The predicted difference between men and women would be 1.7 standard deviations compared to only .4 standard deviations in the bivariate analysis.

\footnotetext{
${ }^{10}$ Personal interview, 3 May 1995, Columbus, Ohio.
} 
$\equiv$ TABLE 3

Regression Analysis of Gender, Legislative Professionalization and Control Variables on Collaborative Leadership Style

Collaborative Committee Management Style

Unstandardized Coefficient

b Std. Error t

\begin{tabular}{lccc}
\hline Sex (Female =1) & 8.397 & 3.172 & $2.647^{* *}$ \\
Years in Legislature & .016 & .053 & .297 \\
Age & -.042 & .034 & -1.257 \\
Legislative & -.089 & .002 & $-4.660^{* * *}$ \\
$\quad$ Professionalization & & & \\
Party (Democrat=1) & .598 & .641 & .932 \\
\% Women in Legislature & .018 & .009 & $2.001^{*}$ \\
Women's Power & -.969 & .723 & -1.339 \\
\% Women x Sex & -.030 & .014 & $-2.184 *$ \\
Women's Power x Sex & 2.627 & 1.127 & $2.332 *$ \\
Community / Volunteer & .492 & .747 & .659 \\
$\quad$ Experience & & & \\
(Constant) & 37.158 & 2.704 & $13.743^{* * *}$ \\
R Square & .153 & & \\
Adjusted R & .119 & & \\
F & $4.529 * * *$ & & \\
$\mathrm{~N}$ & .262 & & \\
\hline
\end{tabular}

${ }^{*} \mathrm{p}<.05,{ }^{* *} \mathrm{p}<01,{ }^{* * *} \mathrm{p}<001$.

Note: Legislative professionalization is an index based on legislator pay, staff members per legislator, and total days in session as developed by Squire (1992).

As hypothesized, the percentage of women in a legislature is associated with different effects for men and women chairs. The positive $b$ for percentage of women legislators $(b=.018, p=.046)$ conveys that as the percentage of women increases, men's collaboration scores, controlling for other variables, increase. The $b$ for the interaction of percentage of women and sex (-.030) conveys the differential impact. As the percentage of woman increases women's collaboration scores decrease $(b=-.012, p<.030)$; this coefficient is derived by subtracting the $b$ for the interaction term from that for percentage of women. While at first blush counter-intuitive, this small effect may reflect the fact that more women in a legislature does not lead automatically to greater likemindedness and in fact the reverse may be true. 
As expected, women's power also produces different effects on men than women. The negative $b$ for women's power $(-.969)$ conveys that as women's power increases, men's collaboration trends modestly downward. The significant interaction between women's power and sex $(b=2.627, p=.022)$ conveys the differential impact. As women's power increases, women's collaboration increases $(b=1.610)$; this coefficient is derived by subtracting the $\mathrm{b}$ for the interaction from that for women's power.

Table 3 reveals a strong negative association between more professionalized legislatures and the collaborative style. As hypothesized, as professionalization increases, scores on the collaboration scale decline significantly $(b=-.089, p=$ .000 ). The impact of legislative professionalization, therefore, is a significant negative predictor of collaborative leadership even when controlling for other variables. The multivariate analysis provides strong support for the view that institutional context is an important determinant of collaborative leadership. Finally, Table 3 reveals no significant effect of community/volunteer experience on collaborative styles when controlling for other variables.

\section{DisCUSSION}

Returning to the hypotheses that directed this inquiry, the analysis supports the expectation that women committee chairs are more collaborative in their leadership style than men. Compared to their male colleagues, women committee chairs on average identify more strongly with collaborative leadership styles. In one focus group, an Arizona chairwoman gave this explanation:

\footnotetext{
Women want to make everybody a winner. If a bill comes up and there are people in support of it, and groups opposed to it, I think we are more apt to try to get everybody to sit down around a table and put it in a subcommittee and try to work out the differences. I think the men are more apt to try to shove through what they want. Women kind of go for that win-win, keep-the-peace kind of attitude. ${ }^{11}$
}

The sex differences vary, however, with legislative institutional variables particularly professionalization, sex composition and gender power.

Second, pre-political experiences of civic engagement seem to have little effect on collaborative leadership styles. Women are more likely than their male peers to cite the value of community and volunteer background, but the link between sex and civic engagement probably reflects different gender opportunities leading to public office than committee leadership styles once in office. Community-based or volunteer networks may be critical paths to office

${ }^{11}$ Focus group, July 28, 1994, New Orleans. 
for many women, but institutional norms and gender composition are more important influences on leadership practices than the skills learned through community/volunteer work.

Finally, as predicted, organizational factors in legislatures are key to understanding collaborative modes of committee leadership. These results confirm the work of scholars who direct attention to the gendered nature of organizations and organizational leadership (Acker 1992). Few if any organizations operate without gender being deeply embedded within their practices, procedures, and methods of membership selection and socialization. Conformity to the powerful norms of heretofore mostly male state legislatures represents the simplest and most straightforward explanation for these results. Elsewhere, Stivers (1993: 49) has argued that professionalism in the administrative state presents a dilemma for women in public administration and some of the same implications operate in professionalized legislatures. Stivers argues that professionalism embodies norms of brotherhood that resist diversity and reinforce women's "subordinated, feminized status as other." She concludes ". . . it is not just that professional characteristics are culturally masculine but that in addition they give masculinity an advantage over femininity" (53).

Professionalized legislatures may place women chairs at a disadvantage by favoring more culturally masculine leadership styles. For example, an Iowa senator in an all-male focus group saw women ill-prepared for committee leadership:

My personal motto is: Never compromise until you absolutely have to. I don't compromise readily unless I know I have to. From my experience, they [the women chairs] are not very good at that. In lowa, you tend to get a lot of women legislators who came in later in life. They've raised their kids, and their kids are out of the home now. So they're a little bit older than I was, I came in when I was 33. So my sense is the women can compromise or they can force their way through, but they're not really very good at judging which time to do what. Is this the time to force or is this the time to give in? ${ }^{12}$

What the senator from lowa may see as poor preparation may in fact be the difficulties some women face in adapting more collaborative forms of leadership to the demands of an institution that favors other norms of leadership behavior.

The presence of more women legislators has a very small but significant positive effect on men's collaborative styles, suggesting the possibility that committee leadership is not immutable but rather may become more collaborative as

${ }^{12}$ Focus group, St. Louis, Missouri, July 29, 1996. 
more women enter legislative service. But the change in men's collaborative styles may also reflect changes in a larger context. While agreeing that women have had an influence on their legislative colleagues, a Maryland chairwoman in one focus group also emphasized a broader societal transition from a "command" to a more collaborative style of leadership:

To some extent there is a societal change. There are men coming into leadership positions now who are more used to thinking of trying to build a consensus. They can't rely on simply telling people what to do or giving orders ... the chain of command is simply not as clear as it used to be. In our House, our previous speaker came from a different school and was forced by economic conditions and other things to assume a leadership role in which he felt it was his responsibility to tell people what to do. . . . Some of the guys, committee chairmen, didn't like that and they became more sensitized. ${ }^{13}$

Alternatively, more female legislators may be reflective of women's changing role in the workplace generally. As one Colorado woman noted, "Younger and younger men are elected and they are more used to dealing with women in the workplace. Many of my colleagues have worked in places where women were their bosses." ${ }^{14}$ Thus, the positive influence of more women legislators on collaborative leadership may be more indicative of societal changes, rather than organizational change.

What is more telling is the impact of women's power on collaborative leadership. On this point, the results of the analysis seem to implicate women's power as important to women's policy success (Norton 1995) and as the causal element in Yoder's instrusiveness hypothesis (1991). The focus group discussions suggested how women's power can be translated into collaboration for policy success. In Arizona, a moderate group of female lawmakers earned the appellation "Sue Nation," which described their pivotal bloc of moderate votes on major legislation in the 1994 session. ${ }^{15}$ Similarly, a Virginia woman identified the importance of a formal women's legislative caucus in securing a seat for a woman on the powerful Rules Committee. ${ }^{16}$ The focus groups also provide reminders that numbers are not synonymous with power. One Califomia senator reported that state's women's caucus fell apart over partisan policy differences that became more

\footnotetext{
${ }^{13}$ Focus group, July 17, 1996, St. Louis, Missouri.

${ }^{14}$ Focus group, July 28, 1994, New Orleans, Louisiana.

15 Pocus group, July 28 1994, New Orleans, Louisiana.

${ }^{16}$ Pocus group, July 28 1994, New Orleans, Louisiana.
} 
evident as more women became members of the Legislature. ${ }^{17}$ More women in the Arizona legislature has meant diversity, not uniformity, of opinion. ${ }^{18}$

The analysis also provides some evidence of Yoder's (1991) intrusiveness hypothesis at work: women's power can be threatening to some men and lead to less collaborative styles of leadership. In one focus group, a Texas chairwoman described such circumstances:

We're at the point where we have enough women in leadership, a critical mass, that we try to caucus and inform one another about our bills. We meet across party lines, rural, urban, black, white, brown; every constituency has women representing it in Texas now. That was not the case for many years when there were just a few of us. ... We also have a women's conference committee, it's not for real, we only do it to irritate the men. We just go back in a room by ourselves and talk about something ... and then they're dying to know what we're doing. ${ }^{19}$

Similarly, in Minnesota, where women hold more power as chairs and leaders than in most states that threat took the form of a head-on challenge to the norms of male leadership in 1996. Favoring more collaborative and participatory values in leadership, two female House members published an unprecedented public critique of then-Speaker Irv Anderson, and a third woman called for his ouster as chair of the House campaign committees. ${ }^{20}$ Representatives Mindy Greiling and Alice Hausman described Anderson as "an oldstyle leader who is a master of reward and retribution."

Under the leadership of Speaker Anderson, legislators have been so busy fighting with each other and inflicting wounds that truly important issues have been ignored. . . The two unwritten rules have become, "Whoever yells the loudest wins," and "If you're not with me, you're against me." Anderson protects his inner circle at all cost, at times even to the detriment of the majority of the caucus. He enables his "in-group" members to dominate and excludes full caucus participation so that the ideas and energy of many are

\footnotetext{
${ }^{17}$ Personal interview, July 27,1994, New Orleans.

${ }^{18}$ Focus group, July 28,1994, New Orleans.

${ }^{19}$ Focus group, 30 July 1996, St. Louis, Missouri.

${ }^{20}$ Mindy Greiling and Alice Hausman, "Minnesota House DFL must oust its abusive leadership," 14 April 1996, Saint Paul Pioneer Press, 23A, and Becky Sisco, "Loud and Clear: Women Legislators speak out aginst House leadership," 15-28 May 1996, Minnesota Women's Press, 5.
} 
wasted. A good leader recognizes the strength of a team and produces more than the sum of everyone's resources. ${ }^{21}$

\section{Conclusion}

These results illustrate the importance of moving beyond analysis of sex differences to consider the organizational context of leadership behavior and specifically women's experiences within gendered institutions (Duerst-Lahti and Kelly 1995). Women appear to bring different preparatory experiences to the legislature and favor more collaborative styles of leadership, however, these differences must be understood within their organizational context.

Beyond the gender dimensions suggested by this research, there are other implications. Legislatures generally are professionalizing, and yet the evidence suggests that professionalized legislatures are unfriendly environs for collaborative leadership. The reasons may be several: For women leaders, professionalized environment poses particular performance pressures (Rosenthal 1997). Professionalized legislatures also may not attract legislators who are inclined to share power and to act collaboratively. In addition, professionalized state legislatures seem to foster a distinctive set of values but notably absent among these is the importance of institutional loyalty and thus commitment to bonds of mutuality and collective decision making (Rosenthal 1996a: 189). "Citizen" assemblies, by contrast, seem less driven by competitive and individualistic impulses (Rosenthal 1997). Again, Stivers' (1993: 49) analysis has relevance when she points out: "the hierarchical character of professionalism blocks the potential for genuine dialogue with citizens, whose opinions can more easily be discounted or dismissed because they are not considered expert."

On balance, the results provide little support for Putnam's assertion that "past success at collaboration . . . can serve as a cultural template for future collaboration" (1995a: 67). The exploratory nature of the analysis and the inability to discern among different types of community/volunteer experiences, however, certainly suggests the need for further research. Nonetheless the analysis raises an important normative issue: If Putnam is correct that "joining and trusting" go hand in hand to create social capital in society, then it is cause for concern that experiences of civic engagement are less valued by some political leaders. While the analysis does not connect "social capital" with collaborative styles, it is still noteworthy that women in legislatures tend to value these experiences more heavily.

Putnam's work suggests a normative preference for collaborative leadership because of the social trust it engenders. Because many legislative issues

${ }^{21}$ Greiling and Hausman, 23A. 
remain primarily matters of "who gets what, when and how," there will continue to be a place for leaders who are skilled in the arts of bargaining and compromise, and transactional leadership has served legislatures well (Burns 1978). Increasingly, however, legislatures are asked to deal with issues of values around which conflicts seem irreconcilable or for which half a solution is no solution at all. Leaders are needed who are skilled in the process of collaboration - listening, educating, defining shared values, and facilitating mutual problem solving. The question facing legislatures is whether the trend toward professionalization leaves room for development of collaborative skills to meet this challenge.

In sum, the determinants of collaborative leadership styles most strongly implicate gender and organizational factors. The increasing power of women and the trend toward professionalization, however, are contradictory trends that make any prediction about the future of collaborative leadership uncertain.

\section{REFERENCES}

Acker, J. 1992. "Gendered Institutions: From Sex Roles to Gendered Institutions." Contemporary Society 21 (3): 565-69.

Adams, Elizabeth Kemper. 1921. Professional Women Workers. New York: MacMillan.

Bums, James MacGregor. 1978. Leadership. New York: Harper \& Row.

Cantor, Dorothy W., and Toni Bernay with Jean Stoess. 1992. Women in Power. New York: Houghton-Mifflin.

Center for the American Woman and Politics (CAWP). 1996. "Women of Color in Elective Office 1996." Fact sheet from the National Information Bank on Women in Public Office. New Brunswick, NJ: Eagleton Institute of Politics, Rutgers University.

Center for the American Woman and Politics. 1993. "Women State Legislators: Leadership Position and Committee Chairs 1993." Fact sheet from the National Information Bank on Women in Public Office. New Brunswick, NJ: Eagleton Institute of Politics, Rutgers University.

Clemens, Elisabeth S. 1993. "Organization Repertoires and Institutional Change: Women's Groups and the Transformation of U.S. Politics, 18901920." American Journal of Sociology 998: 4 (January), 755-98.

Darcy, R., Susan Welch, and Janet Clark. 1987. Women, Elections, and Representation. New York: Longman.

Dolan, Kathleen, and Lynne E. Ford. 1997. "Change and Continuity Among Women State Legislators: Evidence from Three Decades." Political Research Quarterly 50 (March):137-51. 
Duerst-Lahti, G., and R. M. Kelly, eds. 1995, Gender Power, Leadership, and Governance. Ann Arbor: University of Michigan Press.

Elazar, Daniel J. 1966. American Federalism: A View From the States. New York: Crowell.

Ferree, Myra Marx, and Patricia Yancey Martin. 1995. Feminist Organizations. Philadelphia, PA: Temple University Press.

Fiedler, Fred E. 1967. A Theory of Leadership Effectiveness. New York: McGraw-Hill.

Fletty, Valborg. 1951. Public Services of Women's Organizations. New York: George Banta.

Helgesen, Sally. 1990. The Female Advantage: Women's Ways of Leadership: New York: Doubleday.

Hersey, Paul, and Kenneth T. Blanchard. 1977. The Management of Organizational Behavior, 3rd ed. Englewood Cliffs, NJ: Prentice-Hall.

Ianello, Kathleen P. 1992. Decisions Without Hierarchy. New York: Routledge. Jones, Jacqueline. 1990. "The Political Implications of Black and White Women's Work in the South 1890-1965." In Louise A. Tilly and Patricia Gurin, eds., Women, Politics, and Change. New York: Russell Sage Foundation. Jewell, Malcolm, and Marcia Lynn Whicker. 1994. Legislative Leadership in the American States. Ann Arbor: University of Michigan Press.

Kanter, Rosabeth Moss. 1977. Men and Women of the Corporation. New York: Basic Books.

Kurtz, Karl. 1992. State Legislatures: Progress, Problems, and Possibilities. Denver, CO: National Conference of State Legislatures and the Eagleton Institute of Politics.

Levine, Susan.1995. Degrees of Equality. Philadelphia, PA: Temple University Press.

Lunneborg, Patricia. 1990. Women Changing Work. Westport, CT: Greenwood Press.

March, James G., and Johan P Olsen. 1989. Rediscovering Institutions: The Organizational Basis of Politics. New York: Free Press.

Norton, Noelle. 1995. "Women, It's Not Enough to Be Elected: Committee Position Makes a Difference." In Georgia Duerst-Lahti and Rita Mae Kelly, eds., Gender Power, Leadership and Governance. Ann Arbor: University of Michigan Press.

Putnam, Robert D. 1993. "The Prosperous Community: Social Capital and Public Life." The American Prospect Spring: 35-42

-1995a. "Bowling Alone: America's Declining Social Capital." Journal of Democracy 6 (January): 65-78. 
1995b. "Tuning In, Tuning Out: The Strange Disappearance of Social Capital in America." PS: Political Science \& Politics December: 664-83.

Rosener, Judith B. 1990. "Ways Women Lead." Harvard Business Review 68: 119-25.

Rosenthal, Alan. 1996. "State Legislative Development: Observations from 'Three Perspectives." Legislative Studies Quarterly 21 (2): 169-98.

Rosenthal, Cindy Simon. 1997. "A View of Their Own: Women's Committee Leadership Styles and State Legislatures." Policy Studies Journal 24:4.

Scott, Anne Firor. 1993. Natural Allies: Women's Associations in American History. Urbana: University of Illinois Press.

Sharkansky, Ira. 1969. "The Utility of Elazar's Political Culture." Polity 2 (1): 67-83.

Spalter-Roth, Roberta, and Ronnee Schreiber. 1995. "Outsider Issues and Insider Tactics: Strategic Tensions in the Women's Policy Network During the 1980s" In Myra Marx Ferree and Patricia Yancey Martin, eds., Feminist Organizations. Philadelphia, PA: Temple University Press.

Squire, Peverill. 1992. "Legislative Professionalization and Membership Diversity in State Legislatures." Legislative Studies Quarterly 17 (1): 69-79.

Stivers, Camilla. 1993. Gender Images in Public Administration. Newbury Park, CA: Sage.

Verba, Sidney, Key Lehman Schlozman, and Henry E. Brady. 1995. Voice and Equality: Civic Voluntarism in American Politics. Cambridge, MA: Harvard University Press.

Thomas, Sue. 1994. How Women Legislate. New York: Oxford University Press. Woloch, Nancy. 1994. Women and the American Experience: Volume Two from 1860, 2nd ed., New York: McGraw-Hill.

Woo, Lillian. 1994. "Today's Legislators: Who they Are and Why They Run." State Legislatures 20: 28-33.

Yoder, Janice D. 1991. "Rethinking Tokenism: Looking Beyond Numbers." Gender E Society 5 (June) 178-92.

Received: November 14,1997

Accepted: June 17, 1998

csrosenthal@ou.edu 